\title{
Flotação por ar dissolvido no pós-tratamento de efluentes de reatores anaeróbios utilizando cloreto férrico e tanino vegetal
}

\section{Ana Letícia Kengerski ${ }^{1}$,*, Ana Cé ${ }^{2}$, Mirelly Manica ${ }^{1}$, Carlos Raphael Pedroso ${ }^{1}$ e Carlos Magno de Sousa Vidal ${ }^{1}$}

${ }^{1}$ Universidade Estadual do Centro-Oeste (UNICENTRO). Departamento de Engenharia Ambiental. Rodovia PR-153, km 7, S/№. Riozinho. Irati-PR, Brasil (CEP 84500-000). *E-mail: anakengerski@hotmail.com.

2Universidade Tecnológica Federal do Paraná (UTFPR). Departamento de Engenharia Ambiental. Linha Santa Bárbara, S/№. Francisco Beltrão-PR, Brasil (CEP 85601-971).

Resumo. Os reatores anaeróbios de fluxo ascendente e manda de lodo (UASB) mostram-se como tendência no Brasil uma vez que apresentam diversas vantagens em relação aos sistemas aeróbios convencionais. Entretanto, eles possuem limitações no que diz respeito à remoção de alguns poluentes. Desta forma, o póstratamento desse efluente por coagulação, floculação e flotação por ar dissolvido (FAD), visando à remoção desses poluentes, tem se mostrado uma eficiente alternativa. 0 presente trabalho avaliou inicialmente as condições operacionais do tempo de floculação de 15 min e velocidades de flotação de 5, 10 e 15 cm.min ${ }^{-1}$, com taxa de recirculação de $15 \%$, com dois coagulantes distintos, variando as concentrações de 30 a $100 \mathrm{mg} . \mathrm{L}^{-1}$ para cloreto férrico e de 10 a $50 \mathrm{mg} . \mathrm{L}^{-1}$ para tanino. Após a etapa de otimização, realizou-se novamente os ensaios de coagulação/ floculação e FAD com as dosagens otimizadas de 60 e 100 mg.L-1 para cloreto férrico e 30 e $35 \mathrm{mg} . \mathrm{L}^{-1}$ para tanino. Utilizando-se $35 \mathrm{mg} . \mathrm{L}^{-1}$ de tanino acquapol S5T com tempo de floculação de 15 min e velocidade de flotação de $10 \mathrm{~cm} \cdot \mathrm{min}^{-1}$, foram obtidos resultados satisfatórios na remoção de turbidez, cor aparente, DQO e nitrato, alcançando eficiências de remoção de 98,0\%, $97,6 \%, 66,2 \%$ e $88,0 \%$, respectivamente. 0 coagulante tanino não apresentou eficiência na remoção de fósforo. Entretanto, o coagulante cloreto férrico hexahidratado nas concentrações de 60 e $100 \mathrm{mg} . \mathrm{L}^{-1}$ permitiu $100 \%$ de remoção do fósforo, no entanto apresentou baixa eficiência de remoção de matéria orgânica $(22,6 \%$ e $14,1 \%)$.

Palavras-chave: Coagulante natural; Esgoto doméstico; Tratamento secundário; UASB.

Abstract. Post-treatment of anaerobic reactor effluent by dissolved air flotation using ferric chloride and tannin-based as coagulants. The upflow anaerobic sludge blanket reactors (UASB) show up as trend in Brazil, possessing several advantages

ISSN 2359-1412/RBGAS-2020-0033/2020/7/15/19/257

Rev. Bras. Gest. Amb. Sustent.

http://revista.ecogestaobrasil.net 
compared to conventional aerobic systems. However, they present limitation to the removal of some pollutants. Thereby, the post-treatment of UASB effluent using coagulation, flocculation and dissolved air flotation (DAF) aiming to remove these pollutants has been considered a potential alternative. The present study evaluated initially the following settings: flocculation time of $15 \mathrm{~min}$ and flotation speeds of 5, 10 and $15 \mathrm{~cm} . \mathrm{min}^{-1}$, with $15 \%$ recycling rate. It was studied two different coagulant: ferric chloride hexahydrate (30 to $100 \mathrm{mg} \cdot \mathrm{L}^{-1}$ ) and tannin (10 to $50 \mathrm{mg} . \mathrm{L}^{-1}$ ). After optimization, it was performed the coagulation/flocculation and FAD again, using the optimal dosages of 60 and $100 \mathrm{mg} . \mathrm{L}^{-1}$ of ferric chloride and 30 and 35 mg. $\mathrm{L}^{-1}$ of tannin. By using $35 \mathrm{mg}$. $\mathrm{L}^{-1}$ of acquapol S5T tannin, flocculation time of $15 \mathrm{~min}$ and flotation speed of $10 \mathrm{~cm} \cdot \mathrm{min}^{-1}$ it was obtained satisfactory removal efficiency of turbidity, apparent color, COD and nitrate, reaching 98.0\%, 97.6\%, 66.2\% and $88.0 \%$, respectively. Tannin coagulant did not provide phosphorus removal, on the other hand, the ferric chloride coagulant using both concentration (60 and $100 \mathrm{mg} . \mathrm{L}^{-1}$ ) reached $100 \%$ removal of the phosphorus, but showed low organic matter efficiency removal $(22.6 \%$ and $14.1 \%$, respectively).

Keywords: Natural coagulant; Domestic wastewater; Post-treatment; UASB.

\section{Introdução}

Desde a década de 1980, o uso de reatores anaeróbios (UASB) no Brasil vem crescendo, sobretudo após pesquisas publicadas no Brasil e no exterior (Van Haandel e Lettinga, 1994; Van Haandel e Marais, 1999; Campos, 1999) demonstrarem inúmeras vantagens em comparação com os sistemas aeróbios convencionais (Von Sperling, 2014). Von Sperling (2014) ainda afirma que esses reatores se mostram como uma tendência no Brasil, isso porque possuem vantagens em relação a outros sistemas de tratamento, pois demandam menores volumes globais das unidades, menor consumo de energia, baixo custo de implantação e operação, além de produzirem lodo estabilizado.

Apesar de diversas vantagens e da grande aceitação, os reatores anaeróbios possuem algumas limitações, existindo uma grande dificuldade em produzir de forma isolada efluente dentro dos padrões estabelecidos pela legislação brasileira, dificuldades como: remoção insatisfatória de nitrogênio, fósforo e de patógenos e elevadas concentrações de matéria orgânica no efluente final (Silva et al., 2007). É de grande preocupação ambiental a remoção de nutrientes dos efluentes, pois tais componentes são considerados como um fator de aceleração do processo de eutrofização, principalmente em ambientes mais vulneráveis como lagos e represas.

Neste contexto, vê-se a necessidade de implementação de tecnologias que visem o pós-tratamento desses efluentes e que mostrem eficiência na remoção de nutrientes, matéria orgânica e outros poluentes remanescentes do tratamento convencional. Uma das alternativas disponíveis para este propósito é a flotação por ar dissolvido (FAD), a qual tem se mostrado eficiente na separação de partículas em vários tipos de sistemas de efluente, incluindo no pós-tratamento de reatores anaeróbios (Reali, 1998; Moretti, 2001).

A FAD consiste na remoção das partículas presentes na água e em efluentes por meio da geração de microbolhas de gás, normalmente o ar, formando agregados com uma 
densidade menor que a do líquido. 0 desprendimento do agregado, através do processo FAD, resultará na emersão das partículas à superfície da fase líquida, que poderá ser coletado através de uma operação de raspagem superficial (Di Bernardo et al., 2011).

Silva (2007) ressalta que durante o processo de flotação por ar dissolvido os sais metálicos são os mais empregados na etapa de coagulação, tais como o cloreto férrico, sulfato de alumínio, cloreto de polialumínio, sulfato férrico etc. Todavia, algumas pesquisas têm demonstrado que o uso de coagulantes sintéticos embora seja efetivo, tem demonstrado maior geração de lodo, os quais não são biodegradáveis e acabam por gerar maior impacto ambiental no momento da disposição.

Por sua vez, os coagulantes naturais apresentam-se como alternativa viável, sendo eficiente na remoção de matéria orgânica e patógenos, e na diminuição da geração de lodo (Muyubi e Evison, 1995). A aplicabilidade de coagulantes naturais, como tanino, por exemplo, vem mostrando ser uma alternativa interessante tanto no tratamento de água quanto de efluentes, por serem compostos biodegradáveis e não apresentarem toxicidade (Konradt-Moraes et al., 2007).

Deste modo, o presente trabalho objetivou-se a avaliar o desempenho da flotação por ar dissolvido utilizando-se coagulante sintético (cloreto férrico hexahidratado) e natural (tanino Acquapol S5T) no pós-tratamento de efluente sanitário de reatores anaeróbios UASB, visando à remoção de nutrientes (fósforo e nitrogênio) e matéria orgânica, e a investigar as condições operacionais mais adequadas para aplicação da FAD no pós-tratamento do efluente UASB.

\section{Material e métodos}

O efluente em estudo foi coletado na saída do reator UASB da ETE Rio das Antas, operada pela Companhia de Saneamento do Paraná (Sanepar). A ETE em questão possui

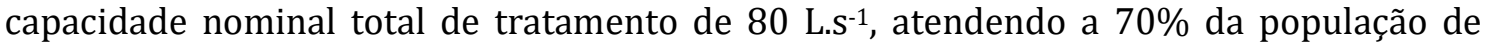
Irati, no Estado do Paraná, Brasil. O fluxograma da referida ETE está representado na Figura 1.

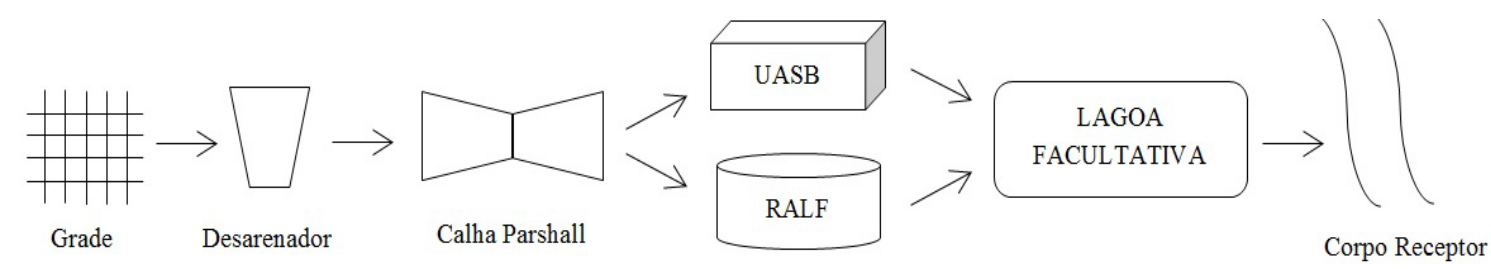

Figura 1. Fluxograma da ETE Rio das Antas - Irati PR.

As amostras coletadas foram encaminhadas para o laboratório, para a realização da caracterização físico-química do efluente em estudo. Os parâmetros analisados foram: $\mathrm{pH}$, temperatura, demanda química de oxigênio (DQO), fósforo, turbidez, nitrato e cor aparente. Para os estudos em laboratório, as amostras foram analisadas pelos métodos estabelecidos em APHA (2012).

Para os testes de coagulação/floculação, foram utilizados os coagulantes: cloreto férrico (metálico) e tanino (natural). Utilizou-se o cloreto férrico hexahidratado $\mathrm{FeCl}_{3} .6 \mathrm{H}_{2} \mathrm{O}$ em pó, com concentração de $10 \mathrm{~g} \cdot \mathrm{L}^{-1}$, e o tanino Acquapol S5T, fornecido pela empresa SETA. O coagulante tanino utilizado é um líquido castanho escuro, com densidade de 1.07 a $1.17{\mathrm{~g} . \mathrm{cm}^{-3}}^{-}$, apresentando pH em média de 2.29 e caráter catiônico.

As amostras coletadas foram submetidas ao tratamento por flotação por ar dissolvido, utilizando-se o equipamento flotatest (marca Nova Ética) com operação em 
batelada para simular o processo, de acordo com a metodologia proposta por Di Bernardo et al. (2002). Os parâmetros fixados para a realização das duas etapas de flotação estão listados na Tabela 1. As condições operacionais adotadas tomaram como base a literatura (Penetra, 1998; Santos, 2006; Constanzi e Daniel, 2002; Quartaroli, 2012) e o estudo foi dividido em duas etapas.

Tabela 1. Configurações da flotação por ar dissolvido adotado para os ensaios.

\begin{tabular}{lc}
\hline Parâmetro & Configuração \\
\hline Gradiente de mistura rápida & $500 \mathrm{~s}^{-1}$ \\
Tempo de mistura rápida & $10 \mathrm{~s}$ \\
Gradiente de floculação & $40 \mathrm{~s}^{-1}$ \\
Tempo de mistura lenta & $15 \mathrm{~min}$ \\
Percentual de recirculação (R) & $15 \%$ \\
Pressão de saturação & $5 \mathrm{bar}$ \\
Tempo de saturação & $15 \mathrm{~min}$ \\
\hline
\end{tabular}

\section{Primeira etapa}

A primeira etapa teve como objetivo otimizar as dosagens dos coagulantes cloreto férrico hexahidratado e tanino acquapol S5T, adequadas para o tratamento do efluente de UASB, testando três velocidades de flotação $\left(\mathrm{Vf}=5 \mathrm{~cm} \cdot \mathrm{min}^{-1}, \mathrm{Vf}=10 \mathrm{~cm} \cdot \mathrm{min}^{-1}\right.$ e $\mathrm{Vf}=15$ cm. min $^{-1}$ ).

Foram realizadas três bateladas de ensaios com o cloreto férrico e três bateladas de ensaios com o tanino acquapol S5T. Nos três primeiros ensaios com o cloreto férrico empregaram-se dosagens de 30 a $100 \mathrm{mg} . \mathrm{L}^{-1}$, variando o pH de 6 a $7.2 \mathrm{com}$ a utilização de 25 a $60 \mathrm{mg} . \mathrm{L}^{-1}$ de ácido clorídrico (HCl) a 0.5 mol.L $\mathrm{L}^{-1}$ e 25 a $75 \mathrm{mg} . \mathrm{L}^{-1}$ de hidróxido de sódio $(\mathrm{NaOH})$ a 0.1 mol. $\mathrm{L}^{-1}$. Nos três ensaios com tanino a dosagem de coagulante testada variou de 10 a 50 mg.L. $\mathrm{L}^{-1}$ sem adição de ácido e/ou base, considerando que o processo com este coagulante não é fortemente dependente do $\mathrm{pH}$, uma vez que não consome a alcalinidade do meio, além de ser eficaz na faixa de pH de 4.5 a 8 (Konradt-Moraes et. al., 2007).

Nesta etapa a eficiência do tratamento foi avaliada com base na remoção de turbidez e cor aparente determinados na caracterização do efluente, antes e depois do tratamento.

\section{Segunda etapa}

Para essa etapa, foi realizada uma nova coleta de efluente, o qual foi levado ao laboratório e caracterizado antes de ser submetido ao tratamento por FAD. Para esta etapa, as dosagens de coagulantes avaliadas foram as que apresentaram melhores resultados de remoção de turbidez e cor aparente na primeira etapa da pesquisa (dosagens otimizadas), e a velocidade de flotação utilizada na segunda etapa foi a de 10 $\mathrm{cm} . \mathrm{min}^{-1}$ visto que a mesma propiciou os melhores resultados de cor e turbidez na primeira etapa. Desta forma, na segunda etapa foram realizados cinco ensaios de coagulação/floculação/FAD, todos em triplicata. 0 primeiro ensaio foi o controle, sem adição de coagulante. No segundo e terceiro ensaios foram avaliadas as dosagens de $60 \mathrm{e}$ $100 \mathrm{mg} . \mathrm{L}^{-1}$ de cloreto férrico. No quarto e quinto ensaios foram empregadas as dosagens de 30 e 35 mg.L-1 para tanino acquapol S5T.

Os parâmetros analisados nessa etapa foram $\mathrm{pH}$, turbidez, cor aparente, DQO, fósforo e nitrato.

Com o objetivo de analisar a existência de diferenças entre os coagulantes utilizados (cloreto férrico /tanino acquapol S5T) e suas dosagens empregadas (Cloreto 
Férrico 60 mg.L-1 e 100 mg.L-1; Tanino Acquapol S5T 30 mg.L-1 e 35 mg.L-1 ), aplicou-se análise estatística utilizando um delineamento inteiramente casualizado onde as variáveis dependentes foram turbidez e cor aparente.

Para avaliar a homogeneidade de variância foi empregado o teste de Bartlett e para confirmar essa premissa, os dados passaram por transformação logarítmica, após foram submetidos a análise de variância de um fator (ANOVA). 0 teste Tukey foi utilizado para assegurar as diferenças entre as médias. A significância para todos os testes foi de $5 \%$ $(\mathrm{p}<0.05)$.

\title{
Resultados e discussão
}

\author{
Resultados da primeira etapa: otimização das dosagens dos coagulantes e da \\ velocidade de flotação \\ Na Tabela 2 encontra-se a caracterização da amostra de efluente do UASB utilizada \\ nos ensaios de FAD na primeira etapa da pesquisa.
}

Tabela 2. Caracterização físico-química da amostra de efluente de UASB utilizada na primeira coleta.

\begin{tabular}{lc}
\hline Parâmetro & Efluente bruto \\
\hline Cor aparente $(\mathrm{uC})$ & 265 \\
Turbidez $(\mathrm{uT})$ & 35 \\
Temperatura do efluente ${ }^{\left({ }^{\circ} \mathrm{C}\right)}$ & 20,6 \\
pH & 7,2 \\
\hline
\end{tabular}

Na Figura 2 encontram-se as concentrações remanescentes de turbidez e cor aparente obtidos na primeira etapa da pesquisa utilizando cloreto férrico ( $a$ e b) e tanino (c e d) como coagulante.

Utilizando-se o coagulante cloreto férrico (Figura $2 \mathrm{a}$ e b), verifica-se que, em comparação com a velocidade de $15 \mathrm{~cm} \cdot \mathrm{min}^{-1}$, as velocidades de flotação $5 \mathrm{~cm} \cdot \mathrm{min}^{-1} \mathrm{e}$ $10 \mathrm{~cm} \cdot \mathrm{min}^{-1}$ apresentaram melhor desempenho na remoção dos parâmetros estudados. Comparando-se as velocidades de 5 e $10 \mathrm{~cm} \cdot \mathrm{min}^{-1}$, não se obteve grande diferença.

É possível observar também que o cloreto férrico demonstrou melhores resultados de remoção de turbidez com a utilização das maiores dosagens $\left(90 \mathrm{mg}\right.$. $\mathrm{L}^{-1} \mathrm{e}$ $100 \mathrm{mg} . \mathrm{L}^{-1}$ ), sendo que os melhores resultados foram obtidos utilizando-se a maior dosagem (100 mg.L-1 $)$. Para a cor aparente, observou-se maiores eficiências de remoção com a utilização das dosagens de $60 \mathrm{mg} . \mathrm{L}^{-1}$ e $100 \mathrm{mg} \cdot \mathrm{L}^{-1}$ de cloreto férrico, sendo que os melhores resultados também foram obtidos utilizando-se a maior dosagem (100 mg.L.- . $^{-}$.

Com a dosagens de $100 \mathrm{mg} . \mathrm{L}^{-1}$ de cloreto férrico e velocidade de flotação de $10 \mathrm{~cm} \cdot \mathrm{min}^{-1}$ foi possível obter remoção média de turbidez e cor aparente de $92,8 \%$ e $88,7 \%$, respectivamente.

Com relação às velocidades de flotação, utilizando-se o coagulante tanino (Figura 2 c e d), verifica-se que todas as velocidades testadas apresentaram desempenho semelhante na remoção de turbidez e cor aparente.

Analisando-se as dosagens de tanino testadas, os melhores resultados tanto de remoção de turbidez quanto de remoção de cor aparente foram com a utilização das concentrações de 30 e $35 \mathrm{mg} . \mathrm{L}^{-1}$ de tanino. Utilizando a velocidade de $10 \mathrm{~cm} . \mathrm{min}^{-1}$, a eficiência média de remoção de turbidez e cor aparente foram respectivamente de $97,1 \%$ e 89,8\%, para dosagem de $30 \mathrm{mg} . \mathrm{L}^{-1}$, e de $96,7 \%$ e 91,7\%, para a dosagem de $35 \mathrm{mg} . \mathrm{L}^{-1}$. 
As maiores dosagens de tanino (40 a 50 mg. $\mathrm{L}^{-1}$ ) não apresentaram remoção significativa de turbidez e cor aparente, quando comparado com as dosagens 30 e 35 mg. $\mathrm{L}^{-1}$, o que pode ser explicado pelo fato que com maiores dosagens houve a formação de flocos de baixa sedimentabilidade.

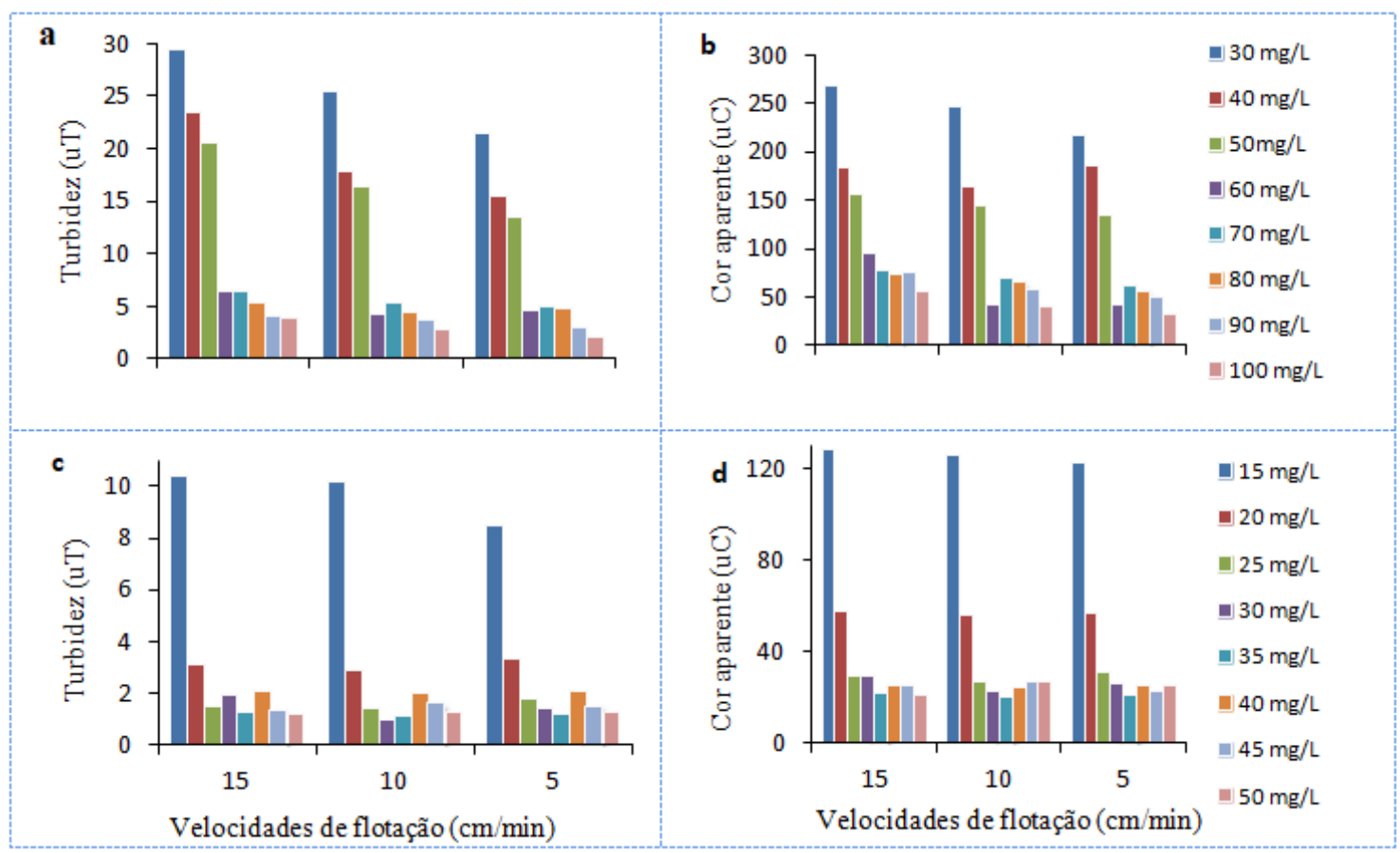

Figura 2. Resultados dos ensaios de turbidez e cor aparente utilizando cloreto férrico hexahidratado (a) e (b) e tanino acquapol S5T (c) e (d) como coagulante.

Desta forma, a primeira etapa do estudo demostrou que para o coagulante cloreto férrico as dosagens que apresentaram melhores resultados na remoção de turbidez e cor aparente foram as dosagens de 60 e $100 \mathrm{mg} . \mathrm{L}^{-1}$. Já para o coagulante tanino, as dosagens de 30 e 35 mg.L-1 proporcionaram maiores remoções de turbidez e cor aparente. Considerando-se eficiência de remoção e tempo necessário para tratamento, escolheu-se como velocidade ótima de flotação $10 \mathrm{~cm} \cdot \mathrm{min}^{-1}$. Portanto, a segunda etapa do estudo será conduzida utilizando-se as dosagens e velocidade de flotação otimizadas na nesta primeira etapa.

Resultados da segunda etapa: Avaliação da eficiência dos coagulantes cloreto férrico e tanino na remoção de cor aparente, turbidez, DQO, fósforo e nitrato

Na Tabela 3 encontra-se a caracterização da amostra do efluente do UASB utilizada na segunda etapa do estudo. 
Tabela 3. Caracterização física e química do efluente bruto da segunda coleta.

\begin{tabular}{lc}
\hline Parâmetro & Efluente bruto \\
\hline Cor aparente $(\mathrm{uC})$ & 600 \\
Turbidez (uT) & 95 \\
Temperatura do efluente $\left({ }^{\circ} \mathrm{C}\right)$ & 22 \\
pH & 7,3 \\
DQO (mg. $\left.\mathrm{L}^{-1}\right)$ & 156 \\
Nitrato $\left(\mathrm{mg} \cdot \mathrm{L}^{-1}\right)$ & 0,168 \\
Fósforo (mg.L & 1,46 \\
\hline
\end{tabular}

Segundo Von Sperling (2014), as concentrações médias de DQO e fósforo e para os efluentes de UASB são de 180 a $270 \mathrm{mg} . \mathrm{L}^{-1}$ e $<4 \mathrm{mg} . \mathrm{L}^{-1}$ respectivamente, portanto, os valores encontrados para o efluente em estudo encontram-se abaixo do citado na literatura, o que pode ser explicado pela diluição do efluente devido à contribuições de infiltração de águas pluviais.

Os valores de cor aparente e turbidez encontram-se elevados em comparação com as amostras da primeira etapa. Isto se deve ao fato que efluentes provenientes de esgoto domésticos são suscetíveis a variações sazonais, visto que variados compostos podem ser acrescentados, portanto, são esperadas variações nas características do efluente em diferentes dias de coleta.

A Figura 4 apresenta os resultados das análises de cor aparente (a) e de turbidez (b) para os diferentes coagulantes e respectivas dosagens.

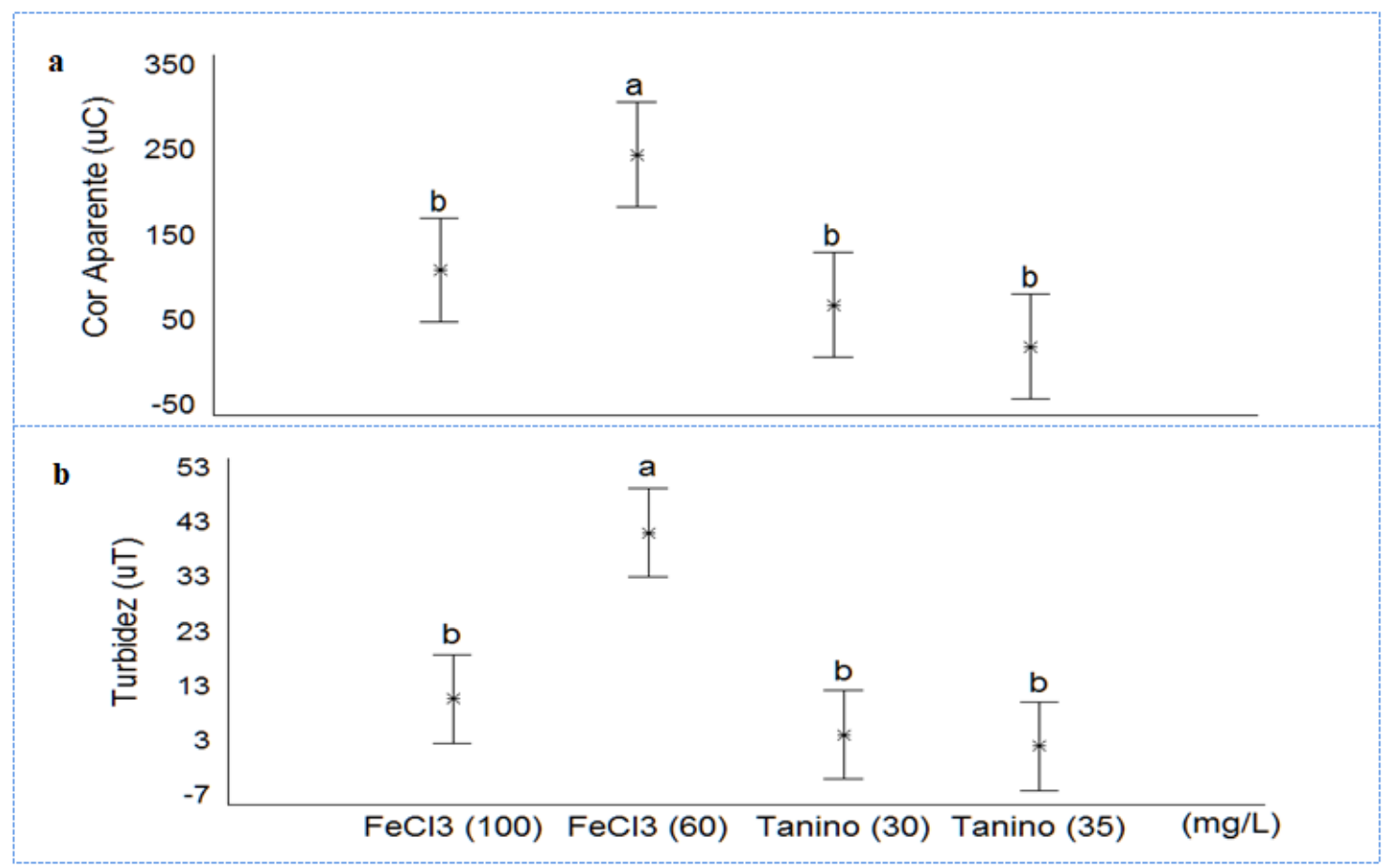

Figura 4. Teste de Tukey a 95\% de significância para diferentes concentrações de cloreto férrico hexahidratado e tanino Acquapol S5T na remocão de cor aparente (a) e turbidez (b) (médias remanescentes seguidas pela mesma letra não diferem estatisticamente entre si). 
As médias de remoção de cor aparente utilizando dosagens de 60 e $100 \mathrm{mg} . \mathrm{L}^{-1}$ de cloreto férrico foi de $60,0 \%$ e $81,3 \%$, respectivamente. Já para o coagulante tanino obtevese médias de remoção de $88,0 \%$ e $97,6 \%$ com as dosagens de 30 e 35 mg. $\mathrm{L}^{-1}$, respectivamente. De acordo com a Figura 4a, observa-se que não houve diferença significativa entre as concentrações médias remanescentes de cor aparente usando o cloreto férrico hexahidratado a $100 \mathrm{mg} . \mathrm{L}^{-1}$ e tanino acquapol S5T a 30 e $35 \mathrm{mg} . \mathrm{L}^{-1}$, e estas apresentaram diferença estatística significativa em relação à dosagem de $60 \mathrm{mg} . \mathrm{L}^{-1}$.

Pelegrino (2011) analisou o emprego de coagulante à base de tanino em sistema de pós-tratamento de efluentes de reator UASB por flotação e utilizando uma dosagem de 65 mg. $\mathrm{L}^{-1}$ de tanino obteve eficiência de $72,2 \%$ de remoção de cor aparente, sendo esta eficiência menor do que a encontrada no presente trabalho.

A clarificação através da flotação por ar dissolvido pode ser empregada quando a água bruta possui cor relativamente alta em comparação à turbidez, pois propicia a remoção de flocos leves, comumente, produzidos após a coagulação e a floculação (Di Bernardo et al., 2011).

Para o parâmetro turbidez, é possível observar na Figura 4b, que a dosagem de 60 mg.L-1 de cloreto férrico hexahidratado foi a que apresentou menor eficiência de remoção de turbidez e foi a única que apresentou diferença significativa em relação às demais. Utilizando-se a dosagem de $35 \mathrm{mg}$. $\mathrm{L}^{-1}$ de tanino acquapol S5T, obteve-se $98,0 \%$ de remoção de turbidez, a qual apresentou-se estatisticamente semelhante a dosagem de $30 \mathrm{mg} . \mathrm{L}^{-1}$ de tanino acquapol S5T e a dosagem de $100 \mathrm{mg} . \mathrm{L}^{-1}$ de cloreto férrico hexahidratado.

A metodologia presente na pesquisa, foi semelhante à utilizada por Dias et al. (2005), que avaliaram a eficiência da aplicação de FAD no pós-tratamento de efluente de reator UASB na ETE Sideral, utilizando cloreto férrico hexahidratado como coagulante. 0 autor obteve uma remoção média de cor aparente e turbidez de 87,0\% e 92,46\%, respectivamente, para as condições de $60 \mathrm{mg} \cdot \mathrm{L}^{-1}$ de cloreto e tempo de flotação de $5 \mathrm{~cm} \cdot \mathrm{min}^{-1}$.

A Tabela 4 apresenta as médias e as eficiências de remoção de DQO, fósforo e nitrato obtidas após tratamento utilizando-se os coagulantes cloreto férrico nas dosagens de 60 e $100 \mathrm{mg} . \mathrm{L}^{-1}$ e tanino nas dosagens de 30 e $35 \mathrm{mg} . \mathrm{L}^{-1}$.

Tabela 4. Caracterização das amostras de efluente do reator UASB após tratamento com coagulante cloreto férrico (60 e $100 \mathrm{mg} . \mathrm{L}^{-1}$ ) e com coagulante tanino (30 e 35 mg.L-1) (valores médios de DQO, fósforo e nitrato e a porcentagem de remoção alcançada com cada tratamento).

\begin{tabular}{|c|c|c|c|c|c|c|c|c|}
\hline \multirow[b]{3}{*}{ Parâmetro } & \multicolumn{8}{|c|}{ Dosagem de coagulante (mg.L $\left.{ }^{-1}\right)$} \\
\hline & \multicolumn{2}{|c|}{$\mathrm{FeCl}_{3}(60)$} & \multicolumn{2}{|c|}{$\mathrm{FeCl}_{3}(\mathbf{1 0 0})$} & \multicolumn{2}{|c|}{ Tanino (30) } & \multicolumn{2}{|c|}{ Tanino (35) } \\
\hline & $\begin{array}{c}\text { Média } \\
\left(\text { mg.L }^{-1}\right)\end{array}$ & $\begin{array}{c}\text { Eficiência } \\
\text { (\%) }\end{array}$ & $\begin{array}{c}\text { Média } \\
\text { (mg.L-1) }\end{array}$ & $\begin{array}{c}\text { Eficiência } \\
\text { (\%) }\end{array}$ & $\begin{array}{c}\text { Média } \\
\left(\mathrm{mg.L}^{-1}\right)\end{array}$ & $\begin{array}{c}\text { Eficiência } \\
\text { (\%) }\end{array}$ & $\begin{array}{c}\text { Média } \\
\left(\text { mg.L }^{-1}\right)\end{array}$ & $\begin{array}{c}\text { Eficiência } \\
\text { (\%) }\end{array}$ \\
\hline DQO & 121 & 22,6 & 134 & 14,1 & 54,0 & 65,6 & 58,0 & 62,6 \\
\hline Fósforo & $<0,01$ & 100,0 & $<0.01$ & 100,0 & 1,46 & 0,0 & 1,46 & 0,0 \\
\hline Nitrato & 0,132 & 21.5 & 0.077 & 54,0 & 0,077 & 54,0 & 0,020 & 88,0 \\
\hline
\end{tabular}

Verifica-se que houve $100 \%$ de remoção de fósforo com a utilização do coagulante cloreto férrico em ambas dosagens. Por outro lado, a aplicação do coagulante tanino acquapol S5T nas concentrações de 30 e $35 \mathrm{mg} \cdot \mathrm{L}^{-1}$, não apresentou eficiência de remoção para o parâmetro fósforo.

De acordo com Machado (2007) o incremento nos valores da concentração do coagulante cloreto férrico eleva a eficiência da remoção do fósforo no processo de flotação 
por ar dissolvido. Já a ineficiência do tanino na remoção de fósforo pode ter sido dada pela baixa capacidade deste em converter a fase solúvel do fósforo em particulado. Pelegrino (2011) constatou a baixa eficiência do coagulante tanino na remoção de fósforo total de esgoto sanitário, entretanto alcançou uma eficiência máxima de $61,2 \%$ de remoção.

Com relação ao parâmetro nitrato, pode-se observar que o melhor resultado de remoção deste foi obtido com a dosagem de $35 \mathrm{mg}^{-\mathrm{L}^{-1}}$ de tanino acquapol S5T, apresentando uma porcentagem expressiva de 88,0\% de remoção.

Não se observou grandes remoções de matéria orgânica com a dosagem de $100 \mathrm{mg} . \mathrm{L}^{-1}$ de cloreto férrico hexahidratado, o que corrobora com o perfil espectrofotométrico mostrado na Figura 5. A dosagem de $60 \mathrm{mg} \cdot \mathrm{L}^{-1}$ de cloreto férrico hexahidratado também resultou em uma baixa média de remoção de matéria orgânica de $22,6 \%$. Já as dosagens de 30 e 35 mg. $\mathrm{L}^{-1}$ de tanino acquapol S5T apresentaram melhores resultados de remoção e semelhantes entre si, sendo de $65,5 \%$ e $66,2 \%$, respectivamente.

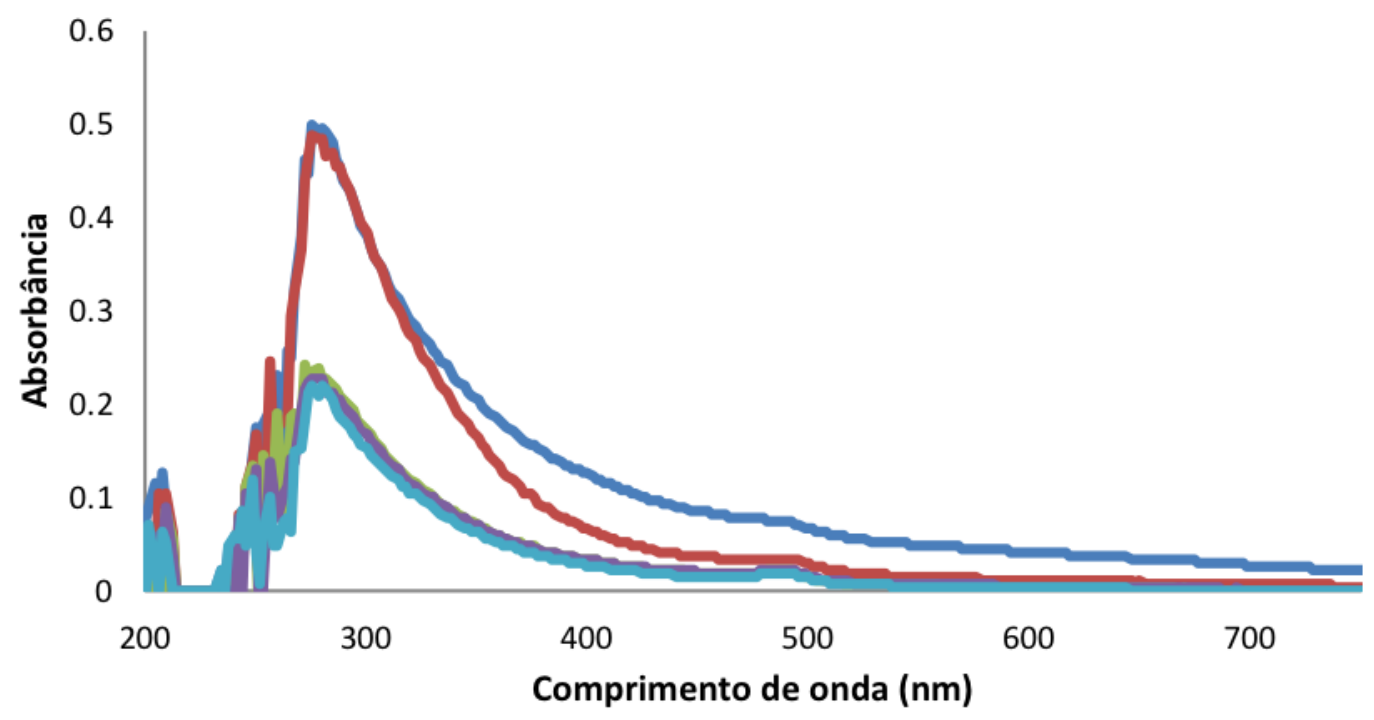

$\longrightarrow$ Bruto $=\mathrm{FeCl} 3100 \mathrm{mg} / \mathrm{L} \longrightarrow \mathrm{FeCl} 360 \mathrm{mg} / \mathrm{L} \longrightarrow \mathrm{S} 5 \mathrm{~T} 30 \mathrm{mg} / \mathrm{L}=\mathrm{S} 5 \mathrm{~T} 35 \mathrm{mg} / \mathrm{L}$

Figura 5. Acompanhamento do perfil espectrofotométrico da amostra de efluente bruto e após o tratamento com flotação por ar dissolvido utilizando tanino e cloreto férrico hexahidratado.

A Figura 5 demonstra o perfil espectrofotométrico das absorbâncias realizadas para o efluente bruto e tratado. Observou-se menores valores de absorbância na região do visível e ultravioleta de 200 a $350 \mathrm{~nm}$, associado a matéria orgânica, para o efluente tratado com o coagulante tanino, corroborando com os resultados descritos na Tabela 4. É possível observar ainda maior redução na região do visível de 350 a $700 \mathrm{~nm}$, a qual está relacionada a presença de cor no efluente, com ambas as dosagens de tanino. Destaca-se, portanto, o coagulante tanino acquapol S5T, que em ambas as dosagens, resultaram em melhores remoções de matéria orgânica.

Segundo Santos (2006) a possibilidade para a ocorrência de baixa remoção de DQO, é que a adição do coagulante cloreto férrico pode resultar na formação de flocos mais densos, que mesmo com vazões de recirculação elevada podem não ser "carregados" pelas microbolhas. Outra razão que o autor cita, é que a coagulação com cloreto férrico 
hexahidratado tenha contribuído para a criação de condições eletrostáticas que resultaram na má formação de aderência das microbolhas nas partículas desestabilizadas.

\section{Conclusões}

A partir dos resultados da primeira etapa do estudo foi possível concluir que as dosagens de 60 e $100 \mathrm{mg} . \mathrm{L}^{-1}$ de cloreto férrico hexahidratado e 30 e $35 \mathrm{mg} . \mathrm{L}^{-1}$ do coagulante tanino acquapol S5T foram as dosagens ótimas para a flotação do efluente, assim como a velocidade de flotação de $10 \mathrm{~cm} \cdot \mathrm{min}^{-1}$.

Os resultados da segunda etapa mostraram que a dosagem de $35 \mathrm{mg} . \mathrm{L}^{-1}$ do coagulante tanino apresentou os maiores percentuais de remoção para turbidez e cor aparente, 97,6\% e 98,0\%, respectivamente, os quais não diferiram estatisticamente das médias obtidas pela aplicação das dosagens de $30 \mathrm{mg} . \mathrm{L}^{-1}$ de tanino e de $100 \mathrm{mg} . \mathrm{L}^{-1} \mathrm{de}$ cloreto férrico. 0 coagulante tanino também se destacou na remoção de DQO, alcançando eficiências de remoção de 65,5\% e 66,2\%, para a dosagem de 30 e 35 mg.L $\mathrm{L}^{-1}$, respectivamente. Com a dosagem de $35 \mathrm{mg} . \mathrm{L}^{-1}$ do coagulante tanino também obteve-se a melhor remoção de nitrato do efluente, alcançando $88 \%$ de remoção. Já com relação à remoção do fósforo, o coagulante tanino não apresentou eficiência. Por outro lado, o coagulante cloreto férrico hexahidratado (nas dosagens de 60 e $100 \mathrm{mg} . \mathrm{L}^{-1}$ ) destacou-se alcançando $100 \%$ de remoção, mostrando elevado potencial quando se objetiva a remoção de fósforo.

\section{Conflito de interesses}

Os autores declaram não haver conflito de interesses.

\section{Referências}

APHA - American Public Health Association. Standard methods for the examination of water and wastewater. 22. ed. Washington, D. C.: APHA, 2012.

Brasil. Resolução CONAMA no 430, de 13 de maio de 2011. Disponível em: <http://www2.mma.gov.br/port/conama/legiabre.cfm?codlegi=646>. Acesso em: 03 mar. 2020.

Campos, J. R. Tratamento de esgotos sanitários por processo anaeróbio e disposição controlada no solo. Rio de Janeiro: PROSAB ABES, 1999.

Costanzi, R. N.; Daniel, L. A. Estudo do tratamento de efluentes de uma fábrica de papel para imprimir visando o reuso por flotação e sedimentação. Engenharia Sanitária e Ambiental, v. 7, n. 3/4, p. 156-160, 2002.

Di Bernardo, L.; Dantas, D. B. A.; Voltan, P. E. N. Tratabilidade da água e dos resíduos gerados em estações de tratamento da água. São Carlos: LDiBe, 2011.

Di Bernardo, L.; Razaboni, J. D.; Rezende, R. J. Emprego de flotação por ar dissolvido para tratamento de despejos líquidos industriais provenientes de laticínios. Revista DAE, n. 130, p 44-53, 2002.

Dias, S. O.; Silva, V. M.; Barbosa, A. J. S.; Rodrigues, R. C.; Pereira, J. A. R. Aplicação da flotação ao pós-tratamento de reator UASB na ETE Sideral, Belém/PA. Revista AIDIS, p. 1-10, 2005. 
Konradt-Moraes, L. C.; Bergamasco, R.; Tavares, C. R. G.; Bongiovani, M. C.; Hennig, D. Avaliação da eficiência de remoção de cor e turbidez, utilizando como agente coagulante os taninos vegetais, com a finalidade de obtenção de água tratada. Anais do $24^{\circ}$ Congresso Brasileiro de Engenharia Sanitária e Ambiental, Belo Horizonte, 2007.

Machado, F. R. Remoção de fósforo na unidade de flotação da estação de tratamento de esgoto. Uberlândia: Universidade Federal de Uberlândia, 2007. (Dissertação de mestrado).

Moretti, R. C. Aplicação da flotação para clarificação final do efluente de um sistema de tratamento de esgoto sanitário constituído de reatores anaeróbios (UASB) seguidos de lagoa aerada. Anais do 21ํㅡㄹ Congresso Brasileiro de Engenharia Sanitária e Ambiental, João Pessoa, 2001.

Muyibi, S. A.; Evison, L. M. Optimizing physical parameters affecting coagulation of turbid water with Moringa oleifera seeds. Water Resources, v. 29, n. 12, p. 2685-2695, 1995. https://doi.org/10.1016/0043-1354(95)00133-6

Pelegrino, E.C.F. Emprego de coagulante à base de tanino em sistema de póstratamento de efluente de reator UASB por flotação. São Carlos: Universidade de São Paulo, 2011. (Dissertação de mestrado).

Quartaroli, L. Aplicação da flotação por ar dissolvido como pós-tratamento de efluente de lodo ativado em uma indústria de papel e celulose. Irati: Universidade Estadual do Centro Oeste, 2012. (Dissertação de Mestrado).

Reali, M. A. P; Penetra, R. G.; Campos, J. R. Influência da floculação na flotação de efluentes de reatores anaeróbios UASB. Anais do XXVI Congresso Interamericano de Ingenieria Sanitária y Ambiental, Lima, 1998.

Santos, H. R. Coagulação/precipitação de efluentes de reator anaeróbio de leito expandido e de sistema de lodo ativado precedido de reator UASB, com remoção de partículas por sedimentação ou flotação. São Paulo: Escola de Engenharia de São Carlos, 2006. (Tese de doutorado).

Silva, M. E. R.; Aquino, M. D.; Santos, A. B. Pós-tratamento de efluentes provenientes de reatores anaeróbios tratando esgotos sanitários por coagulantes naturais e não-naturais. Revista Tecnológica, v. 28, n. 2, p. 178-190, 2007.

Van Haandel, A. C.; Marais, G. 0 comportamento do sistema de lodo ativado: teoria e aplicações para projetos e operação. Campina Grande: Epgraf, 1999.

Van Haandel, A. C.; Lettinga, G. Tratamento anaeróbio de esgotos: manual para regiões de clima quente. Campina Grande: Epgraf, 1994.

Von Sperling, M. Introdução à qualidade das águas e ao tratamento de esgotos. Belo Horizonte: UFMG, 2014.

Informação da Licença: Este é um artigo Open Access distribuído sob os termos da Licença Creative Commons Attribution, que permite uso irrestrito, distribuição e reprodução em qualquer meio, desde que a obra original seja devidamente citada. 